\title{
The Discussion on Field Management on Electric Energy Metering Device
}

\author{
Liu Zhitong ${ }^{1}$, Li Chen ${ }^{1}$, Chang Yuan², Shi Songjie ${ }^{3}$, Xue Jiguang ${ }^{2}$, Liu Gang ${ }^{2}$, Jia Qiuxia ${ }^{4}$, \\ Tian Zhili ${ }^{4}$, Zhan Shuguang ${ }^{4}$, Tang Hui ${ }^{4}$ \\ ${ }^{1}$ Shenyang Power Supply Company, Liaoning Electric Power Company Limited, State Grid, China \\ ${ }^{2}$ Measuring Center, Liaoning Electric Power Company Limited, State Grid, China \\ ${ }^{3}$ Institute Science, Liaoning Electric Power Company Limited, State Grid, China \\ ${ }^{4}$ Fushun Power Supply Company, Liaoning Electric Power Company Limited, State Grid, China
}

Keywords: power measurement, safe operation, technical measures, reliability

\begin{abstract}
Electric measurement is a very important factory enterprise work, it is also the key to the energy measurement and product cost accounting. The quality management of electric energy metering device is a very important work and is also the key to electric power enterprises and users to establish a trust relationship, once the electric energy metering device breaks down and faults, the reliability of the measurement will get in trouble, and cause measurement errors and even interrupt measurement. As it is not able to get the real measurement results, the paper probes into the technical measures for management of electric energy metering device.
\end{abstract}

\section{Introduction}

Electric energy metering device is the general term for electric energy calculating apparatus and auxiliary equipment used for measuring and recording power generation, power consumption, power supply (mutual supply), line loss and customer power consumption. It is directly related to the accuracy and reliability of the trade settlement, such as fair, just and reasonable. the interests of three parties distribution and social economic benefit are impact on generating, power supply, power utilization, it is one of the important basic condition to ensure electric power market to move forward, a fair, just the high quality service can be better provided for users at all levels. ${ }^{[1]}$

\section{The Function of Electric Energy Metering Device}

Power production and other products are different, its characteristic is generating, power supply, power utilization, the three departments are into a continuous system, and it is closely related to each other. How to sell to each other, how to calculate economic, a gage measurement between three departments are needed to calculate the amount of electricity, the device is the electric energy metering device. Without it, generating, power supply, power utilization about three aspects are not sold, and electric energy metering device is very important on the generating, power supply and power utilization. $^{[2]}$

In the power system, generating, power supply and power utilization of each link, the large amounts of electric energy metering device are equipped, it is used to measure the electricity, the factory of electricity, power supply, etc. The basis is provided by improving cost accounting reasonable, making production plan, collecting electricity. In industrial and agricultural production, business operation and each work, management is strengthened, energy is saved, product consumption is assessed, electricity consumption quota is made, the economic effect is improved, the electric energy metering device is the necessary measuring instruments. Increasing with the continuous improvement of people's life, power consumption and electricity meter has gradually become families indispensable electrical instrumentation, sum up all the electricity, without electricity meter. 


\subsection{Improving the Safe and Stable Operation of the Metering Device}

Metering device installation is running on the scene, already suffering from all kinds of disturbance, such as over-voltage, power system load test or mutation and even failure, experiencing natural sunlight wind, rain, especially the test of lightning. Once the defects and faults are not withstood, the reliability of the measurement will get in trouble, causing measurement errors and even interrupt measurement, the real measurement result will not be able to get, affecting fair, reasonable settlement. Therefore, it is necessary to take measures to improve the level of its safe operation, and ensure the real measurement reliable. In order to achieve this purpose, the following measures can be adopted.

\subsection{Guaranteeing Product Quality}

Equipment type selection, order and checking are transformed, cost performance of grid operation electric energy metering devices are made, flowing from the source to eliminate fake products to safe and reliable operation and accurate measurement.

\subsection{Ensuring the Operating Environment}

Environmental factors are on the watt-hour meter equipment of electric energy metering device, the additional error of watt-hour meter is mainly due to the environmental temperature, electromagnetic interference, auxiliary power supply of quality and other factors. Therefore, collection and evaluation of environmental information could be used to run watt-hour meter measuring accuracy of the evaluation of the scene. Moreover, it is necessary to use the specifications for the use of the product and the high temperature and stability requirements must be selected for the products with high thermal stability. The product itself requires reliable grounding of the ground.

\subsection{Making Measurement Special}

In order to reduce the other testing instruments and equipment fault or defect safe to reliable operation of the electric energy metering device and accurate measurement. According to the requirement of the measurement technology management discipline, the secondary circuit will measure a device or independence transform into a "dedicated" measurement, and make the transformer load and power factor of the secondary loop meet the requirements..

\section{Strengthening the Installation Quality Management}

The measurement method of high and low pressure is reasonable and reliable, and the measurement function should accord with the actual situation of power load. The accurate grade of electric energy meter and transformer should meet the need of the expansion of metering capacity, and the important power circuit should be equipped with $0.5 \mathrm{~S}$ level electric energy meter, $0.2 \mathrm{~s}$-class current transformer and 0.2s-class voltage transformer; Error stability, reliability index quantization, multi-communication mode and protocol, error bandwidth, impact load measurement function is increased. $^{[3]}$

\section{Requirements for Measurement Installation Space}

The measuring cabinet (box) shall have enough space to install the electric energy meter, and the transformer and the secondary wiring shall maintain sufficient safety distance and operating space. The door in the metering tank (box) shall have a glass observation window for reading and observing the operation of the meter.

Transformer secondary circuit connects insulated wire, copper wire should be used in a single core of secondary loop current cross-sectional areas of connections according to calculate and determine the rating of the current transformer secondary load, cross-sectional areas is at least less than $4 \mathrm{~mm}^{2}$. For the voltage secondary circuit the sectional area of the connection wire should be determined according to the allowable voltage drop calculation, at least less than $2.5 \mathrm{~mm}^{2}$. The 
secondary loop of the low voltage electricity meter and current transformer is not less than $2.5 \mathrm{~mm}^{2}$.

\subsection{General Installation Specifications of Electricity Meters}

For users with high supply and low meter, the electric distance between the measuring point and the low voltage side of the transformer should not exceed $20 \mathrm{~m}$. The installation height of the electric energy meter for the metering screen, the horizontal center line of the electric energy meter should be within the range of $0.6 \sim 1.8 \mathrm{~m}$. For the measurement box installed on the wall, it is suitable for the range of $1.6 \sim 2.0 \mathrm{~m}$. When loading the meter, it is necessary to strictly follow the drawing construction. The bare part of the incoming line conductor must be inserted into the junction box, and tighten the end button one by one

\subsection{Installation of Table Wiring Principle}

The single-phase power meter must connect the phase wire to the current coil; The three-phase power meter must be connected according to the positive phase sequence; Three phase four wire energy meter must connect neutral line; The input wire and the electric energy meter terminal should be the same metal conductor.

\subsection{Strengthening Training and Improving the Quality of Meter Reading Personnel.}

As the constant progress of power system, measurement technology, the original mechanical watch is gradually replaced by electronic watch, automatic meter reading system is widely used, so we should strengthen the meter reading personnel training, and ensure the metrological work orderly.

\section{Analyzing Management Measures of Electric Energy Metering Devices}

The quality management of electric power metering device is a very important work, and it is also the key of building trust relationship between power enterprises and users. In order to ensure the power equipment to operate in the right way, it is necessary to manage the asset management of electric energy metering device. In order to guarantee the safety of the enterprise property, firstly, the power supply should be responsible for the management of measuring devices within the jurisdiction; Secondly, the power supply should be set up in the area of the power measurement device asset files. After that the metrological verification management is carried out, the power supply should be used by the company to measure the qualified electrical energy measurement device. Only ensuring product quality and ensure the accuracy of measurement. In addition, according to the cycle verification and rotation, the electric energy metering device should be set up after operation. Keep the first hand information for future convenience. There is also the handling abnormal situation of electric energy metering device: 1) the metering device of the transformer substation is responsible by the Marketing Department of the company; 2) the measuring device and special line special transformer in the Taiwan area shall be responsible for the power supply; 3) the low-voltage users shall be responsible for the responsible person in the Taiwan area. The person is responsible for finding the responsible person in the accident, and it is beneficial to cultivate the responsible person's responsibility. Finally, the metering device should be computerized. Computer management can improve the work efficiency, enhance the accuracy and precision of work, but also convenient for computer management through the computer screen the location of the point of failure can be obviously found, and the development trend of the future can bring metering device management.

Electric energy metering device for an electric power enterprise is the effective tool, good management measures can not only ensure the normal operation of the enterprise capital chain, equipment replacement and maintenance costs can be reduced, the service life of equipment is increased. The metering device changes with the change of the load current. It should be a dynamic measuring device and not invertible after a configuration. It should always be checked at any time with the seasonal, power load peak and trough period of electricity load, and adjust accordingly at any time. 


\section{Conclusions}

Along with our country economy has entered a rapid development period, especially since this century, the rapid development of industrialization, urbanization, marketization and internationalization, the heavy industry and power industry is pulled for more than 20 years before the average speed of high-speed growing, trend continues. From now on, the next ten years is the important period of development in our country, the process of industrialization is speeded up, deep processing stage will go into. Along with the adjustment of industrial structure, scientific and technological progress and industrial structure optimization and basic modernization, electricity demand to maintain growth, we should guarantee reasonable electricity metering, reasonable and effective management of electric energy metering device, so only can ensure the normal development of society. Although most of the electric power enterprise is implemented in the daily work of electric energy metering device use and management, the phenomenon of electricity stealing is frequent in order to fundamentally solve this problem, technical equipment measurement is just on the one hand, on the other hand, from the moral level to strengthen moral education. As the development of the society, the increasingly progress of science and technology, better and more advanced measuring equipment in electric power enterprises will be very good solution to this problem.

\section{References}

[1] Weng Limin, Chen Lingxin, Jin Jianfeng. Performance indicators and improvement methods of power quality [J]. Power capacitors, 2004 (01): 120- 123.

[2] Wu Chaohui. Discussion on urban distribution network planning [J]. Guangdong power, 2002 (4): 19-21.

[3] Zhou Yuan. Research on intelligent decision support system and co- algorithm of urban distribution network planning based on GIS [D]. Chongqing: chongqing university, 2004:24-31.

[4] Bao Weidong, Liu Bing. On-site verification method of electric power metering device [J]. Electrical measurement and instrumentation, 2006.

[5] Ruan Zhijun. Field calibration research and error analysis of electric energy metering devices. Enterprise technology development, 2012. 